\title{
LAS CANCIONES DE JOAQUÍN SABINA Y SUS LIBROS DE POEMAS: VARIANTES Y REESCRITURAS
}

\author{
JOAQUÍN SABINAS'S SONGS AND BOOKS OF POEMS: VARIANTS AND \\ REWRITINGS
}

\author{
Pablo NúÑez Díaz \\ Universidad de Valladolid \\ ndpablo@uva.es
}

Fecha de recepción: 14-06-2021

Fecha de aceptación: 17-08-2021

\section{RESUMEN}

Este artículo se centra en los poemas de Joaquín Sabina que están más estrechamente vinculados a sus canciones. El principal objetivo es señalar las principales variantes entre las versiones de los libros y las de los discos, y estudiar las reescrituras. En los casos más relevantes, se ofrecerá una interpretación de los motivos por los que el autor lleva a cabo los cambios en cuestión y de cómo estos afectan estética y temáticamente a los textos. El corpus analizado incluye, respecto a los álbumes musicales, desde Inventario (1978) hasta Lo niego todo (2017), y, en lo que tiene que ver con los libros, desde Memoria del exilio (1976) — volumen que prácticamente no ha sido estudiado hasta la fecha- hasta Román paladino (2018).

Palabras Clave: Sabina, canciones, poemas, Memoria del exilio, Ciento volando

\section{Abstract}

This paper focuses on the poems of Joaquín Sabina that are most closely linked to his songs. The main aim is to identify key differences between the versions from the books and those in the albums, and to study their rewritings. I select a few notable examples, examine 
the possible reasons why the author made these changes, and discuss their effect on the aesthetics and subject matter of the texts. The corpus includes several musical albums, spanning from Inventario (Inventory) (1978) to Lo niego todo (I Deny Everything) (2017), as well as books, encompassing from Memoria del exilio (Memory of Exile) (1976) —a volume that has barely ever been studied - up to Román paladino (Plain Romance) (2018).

Key Words: Sabina, songs, poems, Memory of Exile, One Hundred Flying

El interés por la obra de Joaquín Sabina (Úbeda, 1949) está ya consolidado en el ámbito de los estudios literarios. Además de los valiosos prólogos de García Montero (2001) y de Benjamín Prado (2002) a Ciento volando de catorce y Con buena letra respectivamente, han de mencionarse, entre otros, los trabajos de Noguerol (1992), Neyret (2002 y 2004), Pérez Costa (2004), el libro de Emilio de Miguel Martínez (2008) sobre los valores literarios de determinadas canciones de Sabina, y el editado por Laín Corona, (2018), en el que se abordan, por ejemplo, los elementos autobiográficos en las canciones del autor (MENÉNDEZ FLORES, 2018), su condición o no de poeta (LAÍN CORONA, 2018), las técnicas y recursos narrativos en sus canciones (MIGUEL MARTÍNEZ, 2018), un «atlas de lugares sabinianos» (ORTUÑO CASANOVA, 2018), los cuatro poemas que publicó en revistas a finales de la década de 1960 (GARCÍA CANDEIRA, 2018) y sus sonetos (NEIRA, 2018). Más recientemente, Rodríguez Pequeño (2020) ha estudiado los mecanismos de ficcionalidad e interdiscursividad en la obra de Sabina. Por su parte, Justo Zamarro González defendió en 2017, en la Universidad de Viena, la tesis doctoral Estética literaria en la obra de Joaquín Sabina: simbología de la desesperación en el cancionero (ZAMARRO GONZÁLEZ, 2017 y 2019), dirigida por Wolfram Aichinger.

No debe sorprender, por tanto, que interese abordar las variantes entre las letras de los discos del cantante y escritor y sus libros de poemas, algo que se llevará a cabo, por primera vez, teniendo en cuenta todos los libros y discos del autor. De este modo, se desarrolla aquí una investigación que permitirá tener una visión más clara de algunas de las confluencias que se producen en las facetas de letrista y de poeta, en sentido estricto, de Joaquín Sabina. En concreto, se señalarán los poemas y las canciones que están más estrechamente vinculados, se indicarán las principales variantes entre la versión del libro y la del disco, y se ofrecerá una interpretación del motivo por el que el autor lleva a cabo los cambios en cuestión y de cómo estos afectan a los textos.

El corpus estudiado incluye, respecto a los álbumes musicales, desde Inventario (1978) hasta Lo niego todo $(2017)^{1}$, y, en lo que tiene que ver con los libros de poemas, desde $M e$ moria del exilio (1976) — que prácticamente no ha sido estudiado a día de hoy — hasta Román paladino $(2018)^{2}$.

1 Salvo indicación en otro sentido, hasta el álbum Dímelo en la calle (2002) cito del libro recopilatorio de las letras del autor, Con buena letra (Sabina, 2002). En caso de haber divergencia en una cita respecto a las canciones grabadas, se indicará. En cuanto a los álbumes posteriores, sigo los libretos de los cedés.

2 Quedarán al margen de este estudio las antologías Subjetivo y arbitrario (Rute: Ediciones Experimentales, 1987), Calle Melancolía y otras canciones (Buenos Aires: Espasa Calpe, 1995) y Palo seco (Madrid: Visor, 2017), 


\section{MEMORIA DEL EXILIO}

Memoria del exilio, el primer libro de Joaquín Sabina, publicado en Londres en 1976, en la Editorial Nueva Voz, no es un volumen construido solamente con las letras de lo que dos años más tarde sería el disco Inventario. Resulta evidente que el libro supone más que esto desde el momento en que se tiene en cuenta que está formado por 25 letras de canciones o poemas, mientras que el disco contiene solo diez temas. Los textos de Memoria del exilio que aparecen como canciones en Inventario son «40 Orsett Terrace» (p. 16) ${ }^{3}$; «Canción para las manos de un soldado» (pp. 17 y 18); «[Nos enseñaron a tener paciencia...]» (p. 22), publicada en el disco como «Donde dijeron digo decid Diego»; «Inventario» (pp. 23 у 25); «Mi vecino de arriba» (pp. 31 y 32); «Tango del quinielista» (p. 38); y «1968» (pp. 45 y 46). En la quinta estrofa de «Inventario» (p. 23), en Memoria del exilio se lee «el tren que se interpuso entre nosotros» (al igual que en De lo cantado y sus márgenes), verso que en la canción del disco Inventario y en el libro Con buena letra pasó a ser: «la ceniza que queda, los despojos». Por tanto, Con buena letra, en 2001, recupera la lectura original de la canción de 1978, obviando la modificación ofrecida por De lo cantado y sus márgenes en 1986. Respecto a «Mi vecino de arriba», en Memoria del exilio aparece en heptasílabos, y en Con buena letra está en alejandrinos, produciéndose, de esta manera, la reducción en el número de versos.

En lo que se refiere al «Tango del quinielista», los cambios que el autor introdujo en la versión grabada en Inventario muestran una revisión a conciencia del poema, que no hace sino alejarlo más de un hipotexto. El propio autor considera que la canción es un «tango fallido» (SABINA, 2002: 30). Como han señalado González Lucini (2006: 560) y García Candeira (2018: 232), su origen está en el poema «Todas las tardes de domingo muere una flor amarilla en los tejados», publicado en la revista Poesía 70 en 1969. De ahí que Sabina, en anotación manuscrita en el libro Con buena letra, señale que «[f]ue primero poema vallejiano» (SABINA, 2002: 30). Ahora, la consulta de Memoria del exilio permite contar con un texto intermedio, fechado en 1975, que revisa el poema de 1969 y del que Sabina publicará, asimismo, una nueva revisión en Inventario. Si en el poema de 1969 el quinielista recuerda en el cine su mala suerte viendo a «Claudia / Cardinale, Las Vegas, el Ferrari», la lectura de Memoria del exilio es «Claudia Cardinale / y las Vegas», y en la canción de Inventario «Marlon Brando» es quien en la pantalla «baila un tango en París» (SABINA, 2002: 30). Último tango en París, dirigida por Bernardo Bertolucci, había sido estrenada en 1972, pero en España no lo fue hasta después de la muerte de Franco; de ese mismo año es la primera parte de El Padrino, de Francis Ford Coppola, también con Brando como actor protagonista. En cuanto al endecasílabo final, que en las dos primeras versiones es «donde agonizan todos los recuerdos», en la canción pasa a ser finalmente «donde agoniza el corazón del tiempo» (SABINA, 2002: 30).

que no fueron preparadas por Sabina; el mencionado Con buena letra, que, en sus ediciones sucesivas, supone una recopilación estricta de las letras; Muy personal (Barcelona: Planeta, 2013), formado por dibujos del autor acompañados de anotaciones, y Garagatos (Barcelona: Artika, 2016, 2 vols.), que es esencialmente un libro artístico.

3 En el caso de los poemas de los libros de Sabina estudiados, se indicarán directamente los números de página, simplificando así el sistema de referencia. 
«Canción para las manos de un soldado» muestra pequeños cambios con respecto al tema musical: en la estrofa que se refiere a un cacique, en el libro leemos que este «luce su mano un anillo / y su corbata un rubí» (p. 16), mientras que en la canción se dice: «con lo que su mano tira / cuántos podrían vivir», lo que enfatiza el contenido de denuncia social. Más significativo es el caso de «Sobre el turismo y otros modos de liberarse» (pp. 41 y 42), del que surgirá la canción «Cómo decirte, cómo contarte», incluida en el disco en directo Joaquín Sabina y Viceversa (1986). La protagonista de la canción «vino a Madrid buscando el éxito y a lo más a que llegó su aventura fue a encadenar una sucesión de tumbos sin sentido» (MIGUEL MARTÍNEZ, 2008: 49), y la protagonista del poema o letra de canción de Memoria del exilio hizo lo propio con destino a Londres y al día siguiente partirá para París. El autor sustituyó el estribillo de la versión del libro por otro nuevo, y rehízo buena parte del texto, manteniendo unos catorce versos, si bien con pequeños cambios. La versión primigenia tiene 59 versos, incluyendo cada repetición del estribillo; la versión de 1986, un total de 56, por lo que la reducción operada, en cuanto a número de versos, es muy leve. En lo referente al sentido, en ambos casos la protagonista, insatisfecha, va cambiando de amores, amigos, aficiones. Sin embargo, en la segunda versión aparecen al menos tres diferencias importantes respecto a la primigenia.

En primer lugar, si cabe plantear la interpretación, como indica De Miguel Martínez (2008: 49), de que Sabina esté actuando en la canción como un «moralista laico», dicha actitud moralizadora todavía sería más clara en la versión de Memoria del exilio. Así, aunque en la canción Sabina da un consejo a la protagonista, «nadie va ayudarte / si no te ayudas tú un poco más», este queda de algún modo aminorado por la pregunta retórica «[q]ué consejos voy a darte yo / que ni siquiera sé cuidar de mí», y por el estribillo, que supone un canto al escepticismo y a la inversión de valores tradicionales sobre el bien y el mal. En cambio, en la primera versión los consejos eran más claros, y no aparecen ni descreimiento hacia los consejos ni el estribillo escéptico.

En segundo lugar, en la versión de Memoria del exilio podría pensarse que la voz que habla en el texto tiene interés amoroso en la protagonista, y que la insatisfacción y la inminente marcha a París de ella le llevan a interpelarla, mientras que en la segunda versión se elimina esta posible exégesis al afirmar Sabina: «tengo ya tan ocupado el corazón, / no queda sitio para ti». Por lo tanto, la segunda versión está reescrita con resabio y cierto desabrimiento, lejos de todo candor.

Por último, la diferencia en la localización del texto, de Londres a Madrid, coincide con los lugares en los que el autor vivía en cada momento (vid. la cronología de la vida de Sabina en MENÉNDEZ FLORES, 2002: 283-287), lo que es coherente con su costumbre de introducir elementos autobiográficos en sus canciones (MENÉNDEZ FLORES, 2018: 13 y MIGUEL MARTÍNEZ, 2018: 89, entre otros). Al mismo tiempo, la preferencia por Madrid y la eliminación de la mención a París pueden estar relacionadas con el triunfo de la movida madrileña, que, como ha señalado Ortuño Casanova (2018: 173), hizo que la referencia de Sabina a París desapareciera «por obsoleta» durante algunos años. 


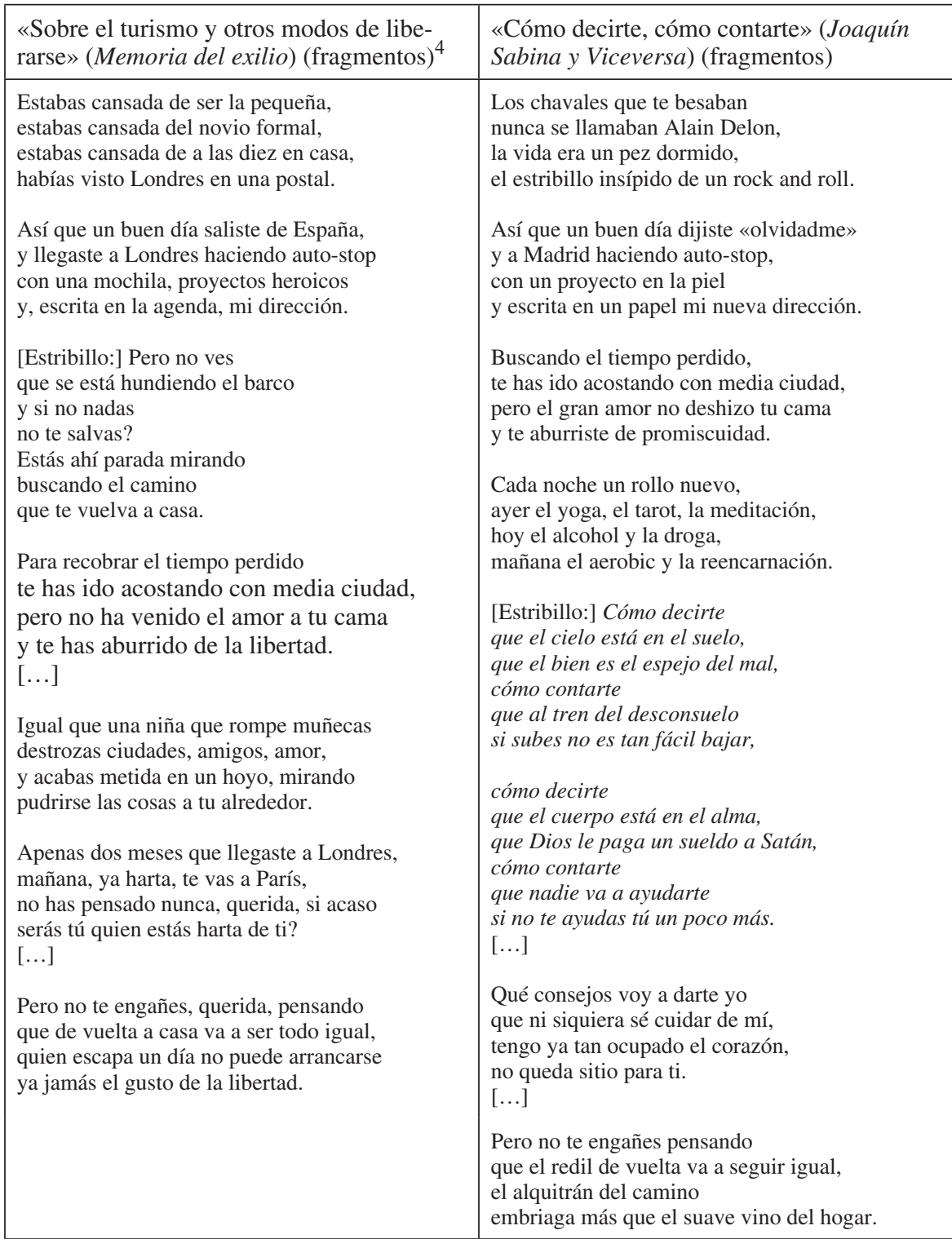

4 Tanto en el caso de las letras de canciones como de los poemas, respetaré las peculiaridades ortográficas que aparezcan en el libro o en el libreto en cuestión. 
Otras dos canciones de Memoria del exilio, que permanecían inéditas, se han publicado en YouTube gracias a grabaciones realizadas en los años setenta en Londres: «Autorretrato con espejo» (pp. 10 y 11) $)^{5}$ «El blues de tu ausencia» (pp. 27 y 28$)^{6}$.

\section{DE LO CANTADO Y SUS MÁRGENES}

De lo cantado y sus márgenes (1986), segundo libro de Joaquín Sabina, fue publicado por la Diputación de Granada en la colección Maillot Amarillo, codirigida por Juan Manuel Azpitarte Almagro y Luis García Montero. El libro De lo cantado y sus márgenes incluye tres secciones bien definidas: la primera de ellas, «De lo cantado», reúne quince letras de canciones que ya se habían publicado en los diferentes discos del cantante; la segunda, «De lo que queda por cantar», cinco que lo serían posteriormente; mientras que la tercera, «De sus márgenes», consta de catorce textos que no fueron nunca canciones. La sección «De lo cantado» la conforman «Inventario» y «40 Orsett Terrace», del disco Inventario (1978); «Pongamos que hablo de Madrid», «Calle Melancolía»—canción escrita en alejandrinos—, «Qué demasiao», «Gulliver» y «Manual para héroes o canallas», de Malas compañías (1980); «Negra noche», de Ruleta rusa (1984); y «Güisqui sin soda (sexo sin boda)», «Cuando era más joven», «Ciudadano cero», «El joven aprendiz de pintor», «Rebajas de enero», «Kung-Fú» $\mathrm{y}$ «Princesa», de Juez y parte (1985). El orden en el que aparecen las letras de estas canciones en el libro resulta revelador: en todas se sigue el orden cronológico de publicación de los discos, salvo en los casos de «Inventario» y de «40 Orsett Terrace», que están las últimas de la sección a pesar de pertenecer al primer disco. Esto es coherente con la falta de entusiasmo del cantante por Inventario ${ }^{7}$.

Respecto a las divergencias entre los textos de esta sección «De lo cantado» y las versiones primigenias de los mismos, destaca el cambio de la segunda y de la última de las estrofas de «Pongamos que hablo de Madrid» (p. 13).

\begin{tabular}{|l|l|}
\hline $\begin{array}{l}\text { «Pongamos que hablo de Madrid» (Malas } \\
\text { compañías) (estrofas segunda y última) }\end{array}$ & $\begin{array}{l}\text { «Pongamos que hablo de Madrid» (De lo } \\
\text { cantado y sus márgenes) (estrofas segunda } \\
\text { y última) }\end{array}$ \\
\hline $\begin{array}{l}\text { Donde el deseo viaja en ascensores, } \\
\text { un agujero queda para mí, } \\
\text { que me dejo la vida en sus rincones... } \\
\text { pongamos que hablo de Madrid. [... }\end{array}$ & $\begin{array}{l}\text { Donde el deseo viaja en ascensores } \\
\text { curo yo las heridas que sufrí } \\
\text { rodando por sus negros escalones... } \\
\text { pongamos que hablo de Madrid. [...] }\end{array}$ \\
$\begin{array}{l}\text { Cuando la muerte venga a visitarme } \\
\text { que me lleven al sur donde nací, } \\
\text { aquí no queda sitio para nadie... } \\
\text { pongamos que hablo de Madrid. }\end{array}$ & $\begin{array}{l}\text { Cuando la muerte venga a visitarme } \\
\text { no me despiertes, déjame dormir, } \\
\text { aquí he vivido, aquí quiero quedarme... } \\
\text { pongamos que hablo de Madrid. }\end{array}$ \\
\hline
\end{tabular}

5 https://www.youtube.com/watch?v=D_-xfjvxVLs, acceso 22-4-2021.

6 https://www.youtube.com/watch?v=X9zJQmKW4wE, acceso 22-4-2021.

7 Vid. las anotaciones manuscritas del autor a las canciones de Inventario en el libro Con buena letra (SA-

BINA, 2002: 28-36). 
La nueva versión de la segunda estrofa no se impuso, y la nueva estrofa final reemplazó a la primigenia en el disco en directo publicado el mismo año que De lo cantado y sus márgenes, esto es, Joaquín Sabina y Viceversa. Por su parte, en el libro Con buena letra se recoge la primera versión, acompañada de la segunda en anotación manuscrita del autor, quien se refiere a ella como «segunda versión». No hay, por tanto, una sustitución de una por la otra, sino la convivencia de ambas. Y resulta evidente la diferencia del mensaje: en una, el poeta quiere que lo entierren en Andalucía, algo que supone un mensaje negativo hacia la vida en la capital; en la segunda, el autor prefiere ser enterrado en Madrid.

Otros cambios de menor importancia en esta sección son los siguientes: en «Gulliver» (p. 26) sustituye «sus costumbres, sus vicios, sus carteras» por «sus perfumes, sus vicios, sus carteras», y «de ser gigante en el país de los enanos» por «de ser el alto en el país de los enanos»; y en «40 Orsett Terrace» elimina la cuarta estrofa - la transformación se produce por reducción-. En ambos casos, y como ya había ocurrido en un ejemplo anterior, el autor recupera la lectura original en el libro Con buena letra, obviando la modificación del volumen De lo cantado y sus márgenes.

Capítulo aparte merece la sección «De lo que queda por cantar», integrada por cinco canciones entonces inéditas. La primera de ellas, «[Hay mujeres...]» (p. 39), se convirtió en «Mujeres fatal» en el disco Joaquín Sabina y Viceversa —interpretada por Jaume Sisa (Ricardo Solfa)—, con un cambio de estribillo. La canción adquiere entonces título, tomado precisamente de la nueva versión del estribillo: «Mujeres fatal». Ocho años más tarde, en el disco Esta boca es mía (1994), dicho estribillo se perfecciona de nuevo.

\begin{tabular}{|l|l|}
\hline $\begin{array}{l}\text { «[Hay mujeres...]» (De lo cantado y sus } \\
\text { márgenes) (estribillo) }\end{array}$ & $\begin{array}{l}\text { «Mujeres fatal» (Joaquín Sabina y Viceversa) } \\
\text { (estribillo) }\end{array}$ \\
\hline $\begin{array}{l}\text { Hay mujeres veneno } \\
\text { hay mujeres imán } \\
\text { hay mujeres consuelo } \\
\text { hay mujeres puñal. }\end{array}$ & $\begin{array}{l}\text { Hay mujeres veneno, mujeres imán, } \\
\text { hay mujeres de fuego y helado metal, } \\
\text { hay mujeres consuelo, hay mujeres consuelo, } \\
\text { hay mujeres consuelo, mujeres fatal. }\end{array}$ \\
\hline
\end{tabular}

\begin{tabular}{|l|}
\hline «Mujeres fatal» (Esta boca es mía) \\
\hline $\begin{array}{l}\text { Hay mujeres veneno, hay mujeres imán, } \\
\text { hay mujeres consuelo, mujeres puñal, } \\
\text { hay mujeres de fuego, } \\
\text { hay mujeres de hielo, } \\
\text { mujeres fatal. }\end{array}$ \\
\hline
\end{tabular}

En la relación que se establece entre estos tres textos, se observa de nuevo cómo la tercera y última versión recupera una lectura original que había sido cambiada en la segunda. Me refiero al tercer verso de la tercera estrofa, «hay mujeres que abren agujeros negros en el alma», que en el disco en directo se cambió por «hay mujeres que exploran secretas estancias del alma», mientras que el verso primigenio es recuperado en Esta boca es mía. El perfeccionamiento de las letras resulta ciertamente habitual en Joaquín Sabina, y en ocasiones lo que hace finalmente es recuperar la versión primera, si el cambio no ha llegado a convencerle. 
La segunda canción de la sección que nos ocupa, «[Desnuda se sentía igual...]», verá la luz en Hotel, dulce hotel (1987), bajo el título «Amores eternos». La versión del disco incluye las dos primeras estrofas - llegarán a ser cuatro-, que se cierran con lo que en el disco será la segunda parte del estribillo («Con ella descubrí que hay amores eternos / que duran lo que dura un corto invierno»). Por otro lado, en la versión primigenia el autor optó por versos más breves que en la versión de la letra de la canción: dos estrofas de cuatro versos cada una constituyen, en la letra de la canción, una sola estrofa de cuatro versos. En el disco se produce un cambio que afecta al sentido, ya que «por encima del hombro» pasa a ser «por encima de mi hombro»: «Pero no sé qué diera / por tenerla ahora mismo / mirando por encima / de mi hombro lo que escribo». El contexto de la canción lleva a pensar que Sabina quería transmitir esta idea también con la primera versión, y que estamos simplemente ante una corrección que busca dejar claro el sentido, evitando que pueda interpretarse que la amada miraba sus escritos con menosprecio. La tercera canción de la sección es la hasta entonces inédita «[Como un perro que lame o ataca sin motivo...]» (p. 41), que Sabina no ha llegado a grabar hasta la fecha; la cuarta, «[De pronto alguna tarde...]» (p. 42), se incluirá en Joaquín Sabina y Viceversa con cambios fundamentalmente en el estribillo:

\begin{tabular}{|c|c|}
\hline $\begin{array}{l}\text { «[De Pronto alguna tarde }] »(\text { De lo cantado } \\
\text { y sus márgenes) (estribillo) }\end{array}$ & $\begin{array}{l}\text { «Zumo de neón» (Con buena letra) (estri- } \\
\text { billo) }\end{array}$ \\
\hline $\begin{array}{l}\text { Basta de urgencias, carne sin sexo, } \\
\text { dame, dame música idiota, } \\
\text { labios de menta, ojos de tedio, } \\
\text { na na na na nadie se toca. }\end{array}$ & $\begin{array}{l}\text { Mar donde flotan } \\
\text { piruetas de bufón, } \\
\text { toreros de salón, } \\
\text { amor de garrafón, } \\
\text { dame, dame música idiota } \\
\text { y zumo de neón } \\
\text { contra la depresión, } \\
\text { todos se miran } \\
\text { na-na-nadie se toca. }\end{array}$ \\
\hline
\end{tabular}

La nueva versión del estribillo se detiene más en la descripción del ambiente en el que se desarrolla la diversión de esa noche, a través de la metáfora del mar en el que flotan los bufones que hacen piruetas, como forma de ridiculizar los bailes observados, o los «toreros de salón», una crítica a la frivolidad y las apariencias.

Por su parte, la quinta y última canción de la sección, «[A ti que te lo haces]» (pp. 43 y 44), es la que cierra Mentiras piadosas (1990), ya con el primer verso como título, «A ti que te lo haces». En la canción, se añade un estribillo en el que el yo lírico introduce la idea de que la amada ha tenido que hacer caso omiso a quienes le desaconsejaban juntarse a él, porque podía ser su ruina (no en vano, lo califican de «menda», lo que sugiere que lo consideran de baja categoría): «A ti que has decidido no prestar atención / a frases del tipo «ese menda, va a ser tu ruina», / a ti que has detenido con un beso el reloj, / a ti que me enfermas, / a ti, que eres mi envenenada medicina».

Asimismo, las estrofas pasan de tener seis a tener ocho versos, y los versos, a su vez, se alargan, dando lugar a varios endecasílabos (por ej., «de baile de disfraces cada día»). Por último, los siguientes versos suponen otro cambio reseñable: 


\begin{tabular}{|c|c|}
\hline $\begin{array}{l}\text { «[A ti que te lo haces... }] » \text { (De lo cantado y } \\
\text { sus márgenes) (fragmento) }\end{array}$ & $\begin{array}{l}\text { «A ti que te lo haces...» (Mentiras piado- } \\
\text { sas) (fragmento) }\end{array}$ \\
\hline $\begin{array}{l}\text { A ti, dulce enemiga, } \\
\text { hermana de fatigas } \\
\text { y derrotas, } \\
\text { vecina de la ausencia, } \\
\text { destino de la urgencia } \\
\text { de mis notas. }\end{array}$ & $\begin{array}{l}\text { a ti que has preferido } \\
\text { vivir como si nada fuera eterno, } \\
\text { a ti que has compartido } \\
\text { conmigo una almohada en el infierno. }\end{array}$ \\
\hline
\end{tabular}

Como puede observarse, la segunda versión pone todavía más el foco que la primera en la lealtad de la amada ante la adversidad compartida, mediante una metáfora hiperbólica de naturaleza religiosa.

\section{CIENTO VOLANDO DE CATORCE}

Ciento volando de catorce fue publicado por la editorial Visor en el año 2001, con prólogo de Luis García Montero. Como sugiere su título, se trata de una colección de cien sonetos. Dicho título guarda relación con «Noches de boda», una de las canciones de 19 días y 500 noches (1999), en la que se dice «que nunca sepas ni cómo, ni cuándo, / ni ciento volando, ni ayer ni mañana». Por su parte, «Manga por hombro» supone una reconstrucción de «Manual para héroes o canallas» (en el mismo sentido, NEYRET, 2002), canción incluida en Malas compañías (1980).

Los poemas «Ay, Carmela» (p. 71) y «Ay, Rocío» (p. 72), dedicados a las hijas del autor, tienen casi idéntico título que las canciones «iAy! Rocío», de Alivio de luto (2005), y «Ay! Carmela», de Vinagre y rosas (2009). Al publicarse cuatro y ocho años después que los poemas, respectivamente, es lógico pensar que se hayan escrito a partir de ellos, aunque no coincidan en un solo verso. La comparación entre los dos poemas y las dos canciones requeriría de un estudio específico. Baste afirmar aquí que una de las principales diferencias estriba en que dichas canciones tienen más emoción y más ternura que los poemas $-\mathrm{y}$, de las dos canciones, Sabina considera que «Ay! Rocío» es la «más emocionante y más corazonada» (SABINA y MENÉNDEZ FLORES, 2006: 341)—.

En el soneto «Así estoy yo sin ti» (p. 81), el autor parte del texto de la canción homónima que abre el disco Hotel, dulce hotel (1987) para continuar la sucesión de símiles, si bien suprime los adjetivos iniciales de los versos, haciendo que la conjunción «como», en lugar de introducir el segundo término de la comparativa, se convierta en una anáfora de comienzo de verso repetida en cada endecasílabo. En el cuerpo del soneto no se incluye la frase «así estoy yo sin ti», que era el estribillo de la canción, y que resulta imprescindible para entender el sentido de los versos. Es el título el que nos da la clave interpretativa. En este caso, el poema deriva claramente de la canción. De nuevo, Sabina opta por aminorar la emoción en el poema, en comparación con la canción. 


\begin{tabular}{|c|c|}
\hline $\begin{array}{l}\text { «Así estoy yo sin ti» (Hotel, dulce hotel) } \\
\text { (fragmentos) }\end{array}$ & «Así estoy yo sin ti» (Ciento volando) \\
\hline $\begin{array}{l}\text { Extraño como un pato en el Manzanares, } \\
\text { torpe como un suicida sin vocación, } \\
\text { absurdo como un belga por soleares, } \\
\text { vacío como una isla sin Robinson. }\end{array}$ & $\begin{array}{l}\text { Para Luis Alberto, Pichi y sus malitos } \\
\text { Como Buster en el apartamento, } \\
\text { con más miedo que Fredo en el padrino, } \\
\text { como el marido fiel de lo que el viento } \\
\text { se llevó con guion de Tarantino, }\end{array}$ \\
\hline $\begin{array}{l}\text { Oscuro como un túnel sin tren expreso, } \\
\text { negro como los ángeles de Machín, } \\
\text { febril como la carta de amor de un preso... } \\
\text { así estoy yo, así estoy yo sin ti. }\end{array}$ & $\begin{array}{l}\text { como helado de fresa y chocolate, } \\
\text { como el acorazado frankestein, } \\
\text { como un primate en el empire state, } \\
\text { como el magnate de citizen Kane, }\end{array}$ \\
\hline $\begin{array}{l}\text { Perdido como un quinto en día de permiso, } \\
\text { como un santo sin paraíso, } \\
\text { como el ojo del maniquí. } \\
\text { Huraño como un dandi con lamparones, } \\
\text { como un barco sin polizones... } \\
\text { así estoy yo sin ti. }\end{array}$ & $\begin{array}{l}\text { como el ángel azul sin escolares, } \\
\text { como Harpo sin arpa ni bocina, } \\
\text { mister president call me Norma Jean, }\end{array}$ \\
\hline $\begin{array}{l}\text { Más triste que un torero } \\
\text { al otro lado del telón de acero. } \\
\text { Así estoy yo, así estoy yo, } \\
\text { así estoy yo sin ti. [...] }\end{array}$ & $\begin{array}{l}\text { como polvos de arroz sin calamares, } \\
\text { como Tarzampanó sin Gelsomina, } \\
\text { como el bastón de Charly sin Chaplin. }\end{array}$ \\
\hline
\end{tabular}

Una reescritura no tan evidente, pero que no pasa desapercibida en una lectura atenta del poemario, es la que ofrece el soneto «Ni con cola» (p. 119), que toma como hipotexto la letra de «40 Orsett Terrace», de Memoria del exilio y del disco Inventario, como se ha indicado. En palabras del autor, se trata de una «versión» (SABINA, 2002: 32). «40 Orsett Terrace» remite a una vivencia de joven adulto (busca piso, tiene granos) y, con ideas y términos ciertamente sencillos («estoy contento»), plantea la experiencia amorosa desde un punto de vista genérico («me enamoro», «me abrazan», «amo», «acaricio»), hasta llegar a la declaración de amor de la estrofa final, poco real y, al mismo tiempo, insistentemente explícita. En cambio, «Ni con cola», manteniendo el tono desenfadado, gana en complejidad y en concreción, al hablar de arrepentirse, apuñalar, dudar, inventarse a la amada, derrapar, equivocarse; introduce elementos de gran expresividad (la metonimia «hago planes con tu ombligo», la perífrasis «me enfado con el padre de mis hijas», el neologismo «viceverso», en referencia al grupo Viceversa, con el que Sabina grabó el disco en directo publicado en 1986), y resuelve la estrofa final con mayor sobriedad que en «40 Orsett Terrace».

\begin{tabular}{|l|l|}
\hline «0 Orsett Terrace» (Inventario) & «Ni con cola» (Ciento volando) \\
\hline Me levanto, bostezo, vivo, almuerzo, & Anochece, deliro, me arrepiento, \\
me lavo, silbo, invento, disimulo, & desentono, respiro, te apuñalo, \\
salgo a la calle, fumo, estoy contento, & compro tabaco, afirmo, dudo, miento, \\
busco piso, hago gárgaras, calculo. & exagero, te invento, me acicalo.
\end{tabular}


Me emborracho, trasnocho, llego tarde, duermo de lado, hablo conmigo, lloro, leo un libro, envejezco, voy al baile, sudo tinta, suspiro, me enamoro.

Llueve, me abrazan, no doy pie con bola, anochece, me compro una camisa, (este verso no pega ni con cola), doy consejos, me rasco, tengo prisa.

Tengo granos, discuto, me equivoco, busco a tientas, no encuentro, me fatigo, me olvido de quién soy, me vuelvo loco, hace frío, amanece, sumo y sigo.

Escupo, voy al cine, me cabreo, escribo, me suicido, resucito, afirmo, niego, grito, dudo, creo, odio, amo, acaricio, necesito.

Te recuerdo, te busco, te maldigo, digo tu nombre a voces, no te veo, te amo, ya no sé lo que me digo, te deseo, te deseo, te deseo.
Acelero, derrapo, me equivoco, nado al crowl, hago planes con tu ombligo, me canso de crecer, me como el coco, cara o cruz, siete y media, sumo y sigo.

Juego huija, me aprieto las clavijas, me enfado con el padre de mis hijas, abuso del derecho al pataleo.

Resbalo, viceverso, carambola, este verso no pega ni con cola, me disperso, te olvido, te deseo.

Por otro lado, una de las secciones en las que se divide Ciento volando de catorce lleva por título «Benditos malditos. Malditos benditos», y está formada por 20 sonetos en los que, como explica Julio Neira (2018: 260), «[s]e bendice lo alternativo y transgresor o a las víctimas de la sociedad, y se maldice lo considerado correcto por los biempensantes, las realidades integradas en el imaginario burgués, los beneficiados de las injusticias sociales». Tomando algunos versos de dicha sección, transformando otros y añadiendo versos nuevos, Sabina construye la letra de la canción «Benditos malditos (al pil pil)», del disco Diario de un peatón, formada por dieciséis estrofas de entre cuatro y seis versos. Llama la atención que las estrofas de seis versos integran alejandrinos y endecasílabos. Además, un ejemplo de transformación de verso lo tenemos en «los adultos que lloran en los cines», del soneto «Benditos malditos VI» (p. 107), que en la canción se convierte en «los cínicos que lloran en los cines». Como estos cínicos forman parte de los que reciben la bendición del autor, no se está criticando la impudencia, sino elogiando el hecho de que tenga sensibilidad ante el arte quien menos se podría esperar que la tuviera.

En cuanto al soneto «Puntos suspensivos» (p. 128), ya había sido leído o recitado de memoria por el cantante como introducción a una de sus canciones, «Nos sobran los motivos», en la gira de la que ha dejado testimonio el disco Sabina y Cía. Nos sobran los motivos (2000). De hecho, lo primero que se escucha en ese doble disco es el poema. Así pues, no resultó extraño que se incluyera en Ciento volando, y en concreto en la sección de amor (o desamor) del libro, «Quien lo probó lo sabe». Lo que quizá llamara la atención es que 
nueve años después del doble disco, y siete años después de la publicación del poemario, apareciera en Vinagre y rosas una canción con los dos primeros cuartetos de «Puntos suspensivos», a los que se sumaron otras cinco estrofas. El tema, titulado «Agua pasada», fue escrito por Sabina y Benjamín Prado, y no surgió como transformación del soneto, sino de manera independiente (PRADO, 2009: 27-45). En el manuscrito del primer boceto, la canción comenzaba con los versos que hoy abren la cuarta estrofa: «Las canciones de amor que no quisiste / andan rodando ya por las aceras» (PRADO, 2009: 37).

\begin{tabular}{|l|l|}
\hline «Puntos suspensivos» (Ciento volando) & «Agua pasada» (Vinagre y rosas) \\
\hline $\begin{array}{l}\text { Lo peor del amor, cuando termina, } \\
\text { son las habitaciones ventiladas, } \\
\text { el solo de pijamas con sordina, } \\
\text { la adrenalina en camas separadas. }\end{array}$ & $\begin{array}{l}\text { Lo peor del amor cuando termina } \\
\text { son las habitaciones ventiladas, } \\
\text { el solo de pijamas con sordina } \\
\text { la adrenalina en camas separadas. }\end{array}$ \\
$\begin{array}{l}\text { Lo malo del después son los despojos } \\
\text { que embalsaman los pájaros del sueño, } \\
\text { los teléfonos que hablan con los ojos, } \\
\text { el sístole sin diástole ni dueño. }\end{array}$ & $\begin{array}{l}\text { Lo malo del después son los despojos, } \\
\text { que embalsaman los pájaros del sueño, } \\
\text { los móviles que insultan con los ojos, } \\
\text { el sístole sin diástole ni dueño. }\end{array}$ \\
$\begin{array}{l}\text { Lo más ingrato es encalar la casa, } \\
\text { remendar las virtudes veniales, } \\
\text { condenar a galeras los archivos. }\end{array}$ & $\begin{array}{l}\text { Lo atroz es no querer saber quién eres, } \\
\text { agua pasada, tierra quemada, } \\
\text { que dé igual esperarte o que me esperes, } \\
\text { que no seas tú entre todas las mujeres, } \\
\text { que la cuenta esté saldada. }\end{array}$ \\
$\begin{array}{l}\text { Lo atroz de la pasión es cuando pasa, } \\
\text { cuando, al punto final de los finales, } \\
\text { no le siguen dos puntos suspensivos... }\end{array}$ & $\begin{array}{l}\text { Las canciones de amor que no quisiste } \\
\text { andan rodando ya por las aceras, } \\
\text { las tocan las orquestas de los tristes } \\
\text { pa que baile don nadie con cualquiera. }\end{array}$ \\
& $\begin{array}{l}\text { Las maletas que llegan sin tu ropa } \\
\text { giran perdidas por los aeropuertos, } \\
\text { la pasión cuando pasa es una copa } \\
\text { de sangre desangrada en el mar Muerto. }\end{array}$ \\
& $\begin{array}{l}\text { Remendar las virtudes veniales, } \\
\text { condenar a galeras los archivos, } \\
\text { cuando al punto final de los finales } \\
\text { no le siguen dos puntos suspensivos. }\end{array}$ \\
& $\begin{array}{l}\text { Peor es no querer saber quién eres, } \\
\text { agua pasada, tierra quemada, } \\
\text { que dé igual esperarte o que me esperes, } \\
\text { que no seas tú entre todas las mujeres, } \\
\text { que la cuenta esté saldada. }\end{array}$ \\
& \\
&
\end{tabular}


Por lo tanto, lo que se hizo fue unir la letra de la canción escrita por Sabina y Prado al soneto del primero. En cuanto al sentido, las estrofas que son propias de la canción ponen en primer plano el sentimiento respecto a la persona a la que ya no se ama, un aspecto que no aparece en el poema: el yo lírico no quiere saber quién es ella, la considera agua pasada, tierra quemada, etc., y las canciones de amor que no quiso «las tocan las orquestas de los tristes / pa que baile don nadie con cualquiera», lo que simboliza que, ante el fracaso sentimental, la labor creativa realizada puede resultar vana. El desconcierto vital se sugiere a través de la personificación de las maletas que giran perdidas por los aeropuertos. En cuanto a la pasión, en el soneto se dice «[1] a atroz de la pasión es cuando pasa», mientras que en la canción se recurre a una metáfora que parece elaborada, mutatis mutandis, a partir del recuerdo de dos elementos bíblicos, la copa de la Santa Cena (Mateo 26, 27-29 y textos paralelos) y el río Nilo convertido en sangre (Éxodo 7, 14-23): «la pasión cuando pasa es una copa / de sangre desangrada en el mar Muerto».

\section{ESTA BOCA ES MÍA}

El libro Esta boca es mía (2005), publicado por Ediciones B con ilustraciones de Gustavo Otero, reúne cincuenta y siete poemas de Sabina aparecidos en la revista Interviú en 2004 y 2005, muy ligados por sus temas a la actualidad política y social. La primera relación de este volumen con las canciones del autor afecta al título, ya que, como es bien sabido, Esta boca es mía da nombre tanto a uno de sus discos, de 1994, como a una de las canciones que lo integran.

Dos de los poemas, «Mi primer pasaporte» (p. 52) y «Mis primeros penúltimos» (pp. 54 y 55), de cinco y dieciséis estrofas de alejandrinos, respectivamente, contienen casi todos los versos que conforman las ocho estrofas de la canción «Me pido primer», que vio la luz ese mismo año en el trabajo Alivio de luto. En la canción, además de añadir un estribillo, Sabina cambia el último verso de la primera estrofa («mi primer adjetivo se llamaba al revés» pasa a ser «mi primer vino tinto se llamaba Noé»), así como tres versos de la última estrofa.

El poema «Oiga, doctor» (p. 70) coincide en el título con la canción «Oiga doctor», del álbum Hotel, dulce hotel, pero, en el caso del poema, el autor no se dirige al médico pidiéndole volver al estado en el que se encontraba antes de ser feliz, sino que la petición tiene que ver con que cuide bien de la salud de Joan Manuel Serrat (bajo el título, la indicación «Matasanos del Serrat»), quien ese mes de noviembre de 2004 sería operado de un tumor ${ }^{8}$.

Por su parte, «Máter España» (p. 88) coincide con la letra de la canción que se publicará ese año en Alivio de luto, salvo que, en el primer verso de la tercera estrofa, en la canción se dirá «Cómplice España» en lugar de «Contrita España». El autor señala bajo el título de la composición: «Cántese con el son de De Gregori, con la voz de Ana Belén».

8 Cf. la noticia «Serrat evoluciona favorablemente tras ser operado de su cáncer de vejiga» (El País, 16-112004), https://elpais.com/cultura/2004/11/16/actualidad/1100559601_850215.html, acceso 18-4-2021. 
Esta autoconciencia de estar presentando a los lectores una letra de canción es coherente con una combinación métrica poco ortodoxa de pentasílabos, hexasílabos, heptasílabos y octosílabos.

Otra relación ciertamente significativa se produce en el caso del poema «Princesa» (p. 98), que, de nuevo, es presentado por su autor como una canción, ya que leemos bajo el título: «(Cántese con la música de ídem)». En efecto, Sabina ofrece aquí una reescritura de la letra de la canción «Princesa», de Juez y parte (1985), para dedicar esta nueva versión a la entonces princesa Letizia.

Por último, vuelve a aparecer en este libro un poema denominado «Benditos malditos», con la estructura de contraposición de bendiciones y maldiciones que ya conocíamos del libro Ciento volando y del disco Diario de un peatón.

\section{A VUELTA DE CORREO}

A vuelta de correo. Sabina epistolar, publicado en 2007 por la editorial Visor, no es un libro de poemas stricto sensu, pero se aborda en este estudio porque reúne más de ochenta poemas del cantante surgidos en correspondencia con cuarenta y un amigos que en su mayoría son escritores o cantantes, así como poemas de sus corresponsales, dibujos, manuscritos y fotografías. La primera relación con sus canciones se establece a partir del título, que es idéntico al de una de las canciones de Diario de un peatón (2003).

En A vuelta de correo aparecen las letras de canciones que ya habían sido grabadas en discos. En primer lugar, la de «¿Quién es Abel, quién es Caín?», el tema con el que Sabina rindió tributo a Luis Eduardo Aute en el disco Mira que eres canalla (2000). Además, encontramos el poema de José Manuel Caballero Bonald «Bolero de la botella vacía» (p. 72), fechado en diciembre de 2004 y dedicado «[a] Joaquín y Jimena», y el de Sabina «Bolero de la última resaca», con fecha de enero de 2005, que juntos dieron lugar a la canción «Dos horas después», de Alivio de luto. Aunque en el libreto del disco ya se indica que la letra de la canción es de Sabina y Caballero Bonald, la publicación de A vuelta de correo permite, primeramente, saber que la letra surge de la unión de dos poemas independientes, y, en segundo lugar, conocer la autoría de cada verso.

\begin{tabular}{|l|l|}
\hline $\begin{array}{l}\text { «Bolero de la última resaca» y «Bolero de la } \\
\text { botella vacía», poemas de } A \text { vuelta de correo }\end{array}$ & $\begin{array}{l}\text { «Dos horas después», canción de Alivio de } \\
\text { luto }\end{array}$ \\
\hline $\begin{array}{l}\text { Joaquín Sabina } \\
\text { Bolero de la última resaca }\end{array}$ & \\
$\begin{array}{l}\text { La tarde consumió su luego fatuo } \\
\text { sin carne, sin pecado, sin quizás, } \\
\text { las noches se agavillan como aves } \\
\text { a punto de emigrar. }\end{array}$ & $\begin{array}{l}\text { La tarde consumió su luego fatuo } \\
\text { sin carne, sin pecado, sin quizás, } \\
\text { la noche se agavilla como un ave } \\
\text { a punto de emigrar. }\end{array}$ \\
\hline
\end{tabular}




\begin{tabular}{|c|c|}
\hline $\begin{array}{l}\text { Y el mundo es un hervor de caracolas } \\
\text { ayunas de pimienta, risa y sal, } \\
\text { y el sol es una lágrima en un ojo } \\
\text { que no sabe llorar. }\end{array}$ & $\begin{array}{l}\text { Y el mundo es un hervor de caracolas } \\
\text { ayunas de pimienta, risa y sal, } \\
\text { y el sol es una lágrima en un ojo } \\
\text { que no sabe llorar. }\end{array}$ \\
\hline $\begin{array}{l}\text { Tu espalda es el ocaso de septiembre, } \\
\text { un mapa sin revés ni marcha atrás, } \\
\text { una gota de orujo acostumbrada } \\
\text { al desdén de la mar. }\end{array}$ & $\begin{array}{l}\text { Tu espalda es el ocaso de septiembre, } \\
\text { un mapa sin revés ni marcha atrás, } \\
\text { una gota de orujo acostumbrada } \\
\text { al desdén de la mar. }\end{array}$ \\
\hline $\begin{array}{l}\text { Y al cabo el calendario y sus ujieres } \\
\text { disecando el oficio de soñar } \\
\text { y la espuela en la tasca de la esquina } \\
\text { y el vicio de olvidar. }\end{array}$ & $\begin{array}{l}\text { Y al cabo el calendario y sus ujieres } \\
\text { disecando el oficio de soñar } \\
\text { y la espuela en la tasca de la esquina } \\
\text { y el vicio de olvidar. }\end{array}$ \\
\hline $\begin{array}{l}\text { José Caballero Bonald } \\
\text { Bolero de la botella vacía } \\
\qquad \text { A Joaquín y Jimena }\end{array}$ & $\begin{array}{l}\text { Por el renglón del corazón } \\
\text { cada mañana descarrila un tren. } \\
\text { Y al terminar vuelta a empezar } \\
\text { dos horas después de amanecer. }\end{array}$ \\
\hline $\begin{array}{l}\text { La noche ha consumido sus botellas } \\
\text { y nadie sabe ya la hora que es. } \\
\text { Han pasado los días como hojas } \\
\text { de libros sin leer. }\end{array}$ & $\begin{array}{l}\text { Tiene la vida un lánguido argumento } \\
\text { que no se acaba nunca de aprender, } \\
\text { sabe a licor y a luna despeinada } \\
\text { que no quita la sed. }\end{array}$ \\
\hline $\begin{array}{l}\text { Tiene la vida algo de argumento } \\
\text { que no se acaba nunca de entender, } \\
\text { la vida es una copa de ese vino } \\
\text { que no quita la sed. }\end{array}$ & $\begin{array}{l}\text { La noche ha consumido sus botellas } \\
\text { dejándose un jirón en la pared. } \\
\text { Han pasado los días como hojas } \\
\text { de libros sin leer. }\end{array}$ \\
\hline $\begin{array}{l}\text { Tu cuerpo es como un verso encandilado } \\
\text { escrito con carmín en la pared, } \\
\text { sabe a licor y a luna retenida } \\
\text { en la copa de ayer. }\end{array}$ & \\
\hline $\begin{array}{l}\text { Siempre acaba la noche cuando empiezan } \\
\text { las vacilantes ganas de beber. } \\
\text { La botella vacía es esa historia } \\
\text { que no termina bien. }\end{array}$ & \\
\hline
\end{tabular}

Como puede observarse, la transformación de los dos hipotextos se produce, por un lado, mediante reducción, ya que de las cuatro estrofas del poema de Caballero Bonald solo dos pasarán a la canción (con algunos cambios). Pero, al mismo tiempo, se añade una nueva estrofa que no estaba presente en los textos primigenios, y de cuyo último verso surgirá el título de la canción: «Por el renglón del corazón / cada mañana descarrila un tren. / Y al terminar vuelta a empezar / dos horas después de amanecer». 
Asimismo, «Violetas para Violeta» (pp. 276 y 277), dedicada a Violeta Parra, es la letra de la canción homónima que se incluye en Vinagre y rosas (2009). Por último, han de mencionarse otros dos elementos del libro que nos ocupa: la inclusión de la letra «Como un dolor de muelas» (pp. 205 y 206), cuya primera parte fue escrita por el Subcomandante Marcos y la segunda por Sabina, y que ya se había publicado como canción en Dímelo en la calle (2002); y la coincidencia en el título del poema «Oiga, doctor» (pp. 335 y 336) y la canción de Hotel, dulce hotel (1987). El poema es el mismo que ya había aparecido en el libro Esta boca es mía (p. 70), dirigido al médico de Serrat.

\section{ESTA BOCA SIGUE SIENDO MÍA}

Esta boca sigue siendo mía, publicado en 2007 por Ediciones B, con ilustraciones de Gustavo Otero, agrupa los 57 poemas de Esta boca es mía, a los que añade otros 127, publicados entre 2005 y 2007. Permanece, prácticamente, la coincidencia entre el título del libro y el título del disco Esta boca es mía y la canción que cierra el álbum, si bien hay una reelaboración de la frase. El poema «Pie de guerra» (pp. 130 y 131) se publicó como canción, el mismo año de su aparición en la prensa, en el disco Alivio de luto, sin cambios relevantes: «el gringo, el bereber» pasa a ser «el debe y el haber»; «el ensueño y la pesadilla» se convierte en «el duermevela y la pesadilla»; y «Montescos, Capuletos de alcanfor», en «el ten con ten, la dicha, el resquemor».

Una nueva reescritura de una canción emblemática del autor se produce con el poema «Pongamos que hablo de París» (p. 176), mientras que del poema «Fun, fun, fun» (p. 188) señala el autor en el subtítulo: «Báilese al vals de mis Noches de Boda», en referencia a la mencionada canción del disco 19 días y 500 noches. Si en otros libros nos encontramos con letras de canciones, desprovistas inevitablemente de su música, en este caso es un poema el que ha de leerse con la música de una determinada canción en mente. Lo mismo ocurre con otros dos poemas: «Luis del Olmo cumple diez mil», del que el autor señala en el subtítulo que debe cantarse «con la melodía de «Pongamos que hablo de...», etc.)» (p. 342), y «Bendita sea la gente» (pp. 354 y 355), del que indica que ha de cantarse «a los acordes de street Melancolía».

También ha de señalarse la aparición, nuevamente, de la fórmula «Benditos...»y «Malditos...», en el segundo de los sonetos que se ofrecen bajo el título común de «Uvas de la ira» (pp. 294 y 295), y dos de los «Treinta aforismos de verano» (p. 358), por estar extraídos de dos canciones: «Moriré sin descendencia como murió mi padre» (en «Pero qué hermosas eran», de 19 días y 500 noches: «Y yo, que había jurado / morir sin descendencia, / como murió mi padre»); y «Bailar es soñar con los pies» (en «Jugar por jugar», de Yo, mí, me, contigo: «y vivir al revés, / que bailar es soñar con los pies»).

\section{ESTA BOCA ES MÍA. EDICIÓN REVISADA Y AMPLIADA}

Joaquín Sabina prosiguió sus colaboraciones en Interviú, dando lugar a una edición ampliada de Esta boca es mía, que recoge los poemas de los dos volúmenes analizados ante- 
riormente —Esta boca es mía y Esta boca sigue siendo mía—, más los nuevos que escribió para la revista entre octubre de 2007 y noviembre de 2009. Varios de estos poemas guardan estrecha relación con el disco Vinagre y rosas (publicado, como se ha indicado, en 2009). De este modo, «Prado, Sabina, Praga», dedicado a Benjamín Prado, es un poema escrito en marzo de 2009, tras regresar del viaje a Praga en el que Sabina y Prado escribieron las letras de Vinagre y rosas, entre ellas, la de la canción «Cristales de Bohemia», de cuyo comienzo está tomada la anáfora «[v]ine a Praga» (sobre el proceso de escritura de la letra de la canción, vid. PRADO, 2009: 47-64).

Asimismo, dos de los poemas son letras del mencionado disco, «Menos dos alas» (pp. 530-531), homenaje a Ángel González —en el disco, esta letra aparece firmada conjuntamente por Sabina y Benjamín Prado—, y «Notas para una crisis» (p. 564), que como canción cambiará de título, «Crisis», y cuyo tema es la crisis económica que asolaba España (un poema anterior del libro lleva precisamente el título «Crisis» (p. 466) y aborda el mismo tema). Por último, el poema «Vinagre y rosas» (p. 566), con la dedicatoria «[p]ara Benjamín Prado, más que nunca», muestra las impresiones del poeta ante la publicación del nuevo disco. Pueden mencionarse también dos poemas, «Como dijo la tortuga» y «Adivina adivinanza», que establecen relación con sendas canciones: «Corre, dijo la tortuga», de Mentiras piadosas, y «Adivina, adivinanza», que el cantante interpreta en el disco en directo La Mandrágora (1981), grabado junto a Javier Krahe y Alberto Pérez.

\section{EL GRITO EN EL SUELO}

El grito en el suelo, aparecido en 2013, reúne los poemas firmados por Joaquín Sabina en el diario Público a lo largo de cincuenta y cuatro domingos, entre enero de 2011 y febrero de 2012, cuando el medio dejó de publicarse en papel. Uno de los poemas del libro, «Y sin embargo Anita» (p. 67), está dedicado a la cantante Ana Belén, a raíz de que esta grabara la canción de Joaquín Sabina «Y sin embargo». Sabina le escribe un poema cuyas primeras cuatro estrofas comentan la canción. Entre otras cosas, afirma que es su «canción de amor / menos contrita» y «una historia de azufre indolente». Por su parte, «Pongamos que hablo de New York» (p. 73) supone una nueva reescritura de la canción «Pongamos que hablo de Madrid», hasta el punto de que aparece la indicación «cántese con la rancia y madrileña melodía». Ha de mencionarse, además, el poema «La orquesta del Titanic» (p. 83), titulado igual que La orquesta del Titanic (2012), disco compuesto y grabado por Sabina y Serrat, y que la canción homónima incluida en dicho trabajo. En cuanto al poema «Como en Chicago» (p. 91) (diciembre de 2011), el autor señala en un subtítulo que se trata de un «proyecto de canción». En YouTube puede escucharse una grabación inédita (subida a la plataforma en julio de 2011) ${ }^{9}$, que, por la voz del artista, podría ser de principios de la década de 1990. El texto se recoge en Con buena letra (p. 313), con modificaciones respecto a la grabación. La versión de El grito en el suelo es, por tanto, la última que el autor ha dado por válida. La diferencia más significativa respecto de la canción es

9 https://www.youtube.com/watch?v=PI109L_Q6UE, acceso 27-4-2021. 
que en los libros se elimina una estrofa que hacía mención al protagonista de El padrino, Vito Corleone, a dos conocidos narcotraficantes y a un cantante internacional, y se añade, en cambio, la siguiente estrofa autobiográfica, de mayor intensidad lírica: «Más de un amigo me dejé en la cuneta / de carreteras secundarias, / cuando volaban sin motor ni receta, / se les fundió la maquinaria. / Y un servidor / con la vergüenza del que sobrevivió» (SABINA, 2013: 91).

\section{EN ROMÁN PALADINO}

El libro En román paladino, publicado en 2018, reúne cuarenta y dos poemas aparecidos en la revista Tintalibre entre 2013 y 2016. Como señala en el prólogo De Miguel Martínez (2018b: 10 y 11), en este corpus hay poemas «de naturaleza lírica», si bien «lo sustancial de aquellas colaboraciones [...] son los poemas de crítica social y política que sitúan a Sabina en la órbita de la poesía satírica de hondas raíces en la literatura española». Destacan los «brindis» con los que se cierran estas colaboraciones, que consisten en un cuarteto, casi siempre en endecasílabos, en que el autor desea el bien a determinados personajes o muestra su satisfacción por aspectos generalmente ligados con la actualidad. Estos «brindis» recuerdan a los «Benditos, malditos» del disco Diario de un peatón y del libro Ciento volando: podrían haber formado parte tanto de la canción como de los poemas, con la debida adaptación sintáctica, ya que los brindis se construyen con la fórmula «brindo por...», en lugar de «benditos sean...».

\section{CONCLUSIÓN}

El lirismo de los primeros poemas de Joaquín Sabina, desde los aparecidos en revistas, parece haberse desarrollado en mayor medida hacia las canciones — sin dejar de estar en determinados poemas, como los de la breve sección «Quien lo probó lo sabe» de Ciento volando-, mientras que la poesía satírica se ha ido convirtiendo en mayoritaria en sus libros de poemas. De este modo, al escribir poemas, Sabina parece tomar cierta distancia respecto a sus letras de canciones, inclinándose tanto por lo satírico como por los versos de circunstancias. Sin embargo, las confluencias entre las letras del autor y sus libros de poemas no han dejado de ser muy estrechas y muestran la inconveniencia de cualquier análisis de su obra que trate de desligar completamente letras de canciones y poemas. En este sentido, a lo largo de toda su trayectoria, existen sobrados ejemplos de canciones nacidas de textos publicados previamente como poemas, y de poemas que se construyen a partir de canciones, amén de los casos específicos de intertextualidad, sobre todo, elementos de las canciones que están presentes en los poemas. En este trabajo se ha constatado que las reescrituras que el autor lleva a cabo tienen implicaciones formales, como la extensión, la métrica, la unión de varios textos, etc., y también de sentido, ya que se observa la evolución del autor en cuanto a madurez y escepticismo, el cambio en su relación con determinadas ciudades o su preferencia por introducir una mayor emotividad en los versos que van a ser cantados. 


\section{REFERENCIAS BIBLIOGRÁFICAS}

García Candeira, Margarita (2018): «La importancia de llamarse Martínez. Sabina, poeta del 68 (cuatro poemas)», Joaquín Sabina o fusilar al rey de los poetas, ed. Guillermo Laín Corona, Madrid, Visor, pp. 203-250.

García Montero, Luis (2001): «El mundo de Joaquín Sabina», Ciento volando de catorce, Joaquín Sabina, Madrid, Visor, pp. 7-15.

González Lucini, Fernando (2006): ... Y la palabra se hizo música. La canción de autor en España. Volumen I, Madrid, Fundación Autor.

Laín Corona, Guillermo (2018): «Sabina ¿no? es poeta», Joaquín Sabina o fusilar al rey de los poetas, ed. Guillermo Laín Corona, Madrid, Visor, pp. 29-88.

- (ed.) (2018): Joaquín Sabina o fusilar al rey de los poetas, Madrid, Visor.

Menéndez Flores, Javier (2002): Joaquín Sabina. Perdonen la tristeza, Madrid, Plaza \& Janés. $1^{\mathrm{a}}$ ed., 2000.

- (2018): «Sabina, el gran tema de Joaquín Martínez», Joaquín Sabina o fusilar al rey de los poetas, ed. Guillermo Laín Corona, Madrid, Visor, pp. 13-28.

Miguel Martínez, Emilio de (2008): Joaquín Sabina. Concierto privado, Madrid, Visor.

- (2018a): «Sabina canta historias (técnicas y recursos de un narrador en canciones)», Joaquín Sabina o fusilar al rey de los poetas, ed. Guillermo Laín Corona, Madrid, Visor, pp. 89-159.

- (2018b): «Sabina, labios como espadas», En román paladino, Joaquín Sabina, Úbeda, Fundación Huerta de San Antonio, pp. 9-12.

Neira, Julio (2018): «Los sonetos de Joaquín Sabina», Joaquín Sabina o fusilar al rey de los poetas, ed. Guillermo Laín Corona, Madrid, Visor, pp. 251-281.

Neyret, Juan Pablo (2002): «Catorce versos dicen que es Sabina: Canción y poesía en «Ciento volando»». Espéculo. Revista de Estudios Literarios, 20, https://webs.ucm.es/info/especulo/numero20/ sabina.html, acceso: 24-4-2021.

- (2004): «Polvo enamorado. Quevedo y el Barroco español en la poética de Joaquín Sabina». Espéculo. Revista de Estudios Literarios, 27, https://webs.ucm.es/info/especulo/numero27/polvoen. html, acceso: 24-4-2021.

Noguerol, Francisca (1992): «El grado pleno de la escritura. (Análisis semiótico de un texto de Joaquín Sabina)», Actas del IV Simposio Internacional de la Asociación Española de Semiótica, vol. I, VV. AA., Madrid, Visor, pp. 429-435.

Ortuño Casanova, Rocío (2018): «Atlas de lugares sabinianos», Joaquín Sabina o fusilar al rey de los poetas, ed. Guillermo Laín Corona, Madrid, Visor, pp. 161-201.

Pérez Costa, Lola (2004): «La melancolía en la obra de Joaquín Sabina». Espéculo. Revista de Estudios Literarios, 26, https ://webs.ucm.es/info/especulo/numero26/index.html, acceso: 24-4-2021.

Prado, Benjamín (2002): «Cómo olvidar una canción de Joaquín Sabina». En Joaquín Sabina, Con buena letra, Madrid, Temas de Hoy, pp. 15-20.

- (2009): Romper una canción. Así se escribió el disco Vinagre y rosas, de Joaquín Sabina, Madrid, Aguilar.

Rodríguez Pequeño, Javier (2020): «Ficcionalidad e interdiscursividad: el arte de lenguaje en Joaquín Sabina». Piedras Lunares. Revista Giennense de Literatura, 4, pp. 97-113.

Sabina, Johquín (1976): Memoria del exilio. Dibujos de Aurelio Buly. Londres, Editorial Nueva Voz. (Edición facsimilar.)

- (1986): De lo cantado y sus márgenes, Granada, Diputación de Granada.

- (2000): Sabina y Cía. Nos sobran los motivos [doble cedé], Madrid, BMG Music.

- (2001): Ciento volando de catorce, $3^{\mathrm{a}}$ ed., Madrid, Visor.

- (2002a): Con buena letra, Madrid, Temas de Hoy. 
- (2002b): Diario de un peatón [cedé], Madrid, BMG Music.

- (2005a): Alivio de luto [cedé], Madrid, Sony BMG Music Entertainment.

- (2005b): Esta boca es mía. Ilustraciones de Gustavo Otero, Barcelona, Ediciones B.

- (2007a): A vuelta de correo, Madrid, Visor.

- (2007b): Esta boca sigue siendo mía. Ilustraciones de Gustavo Otero, Barcelona, Ediciones B.

- (2009): Vinagre y rosas [cedé], Madrid, Sony BMG Music Entertainment.

Sabina, JoAquín (2010): Esta boca es mía. Edición revisada y ampliada. Ilustraciones de Gustavo Otero, Barcelona, Ediciones B.

- (2013): El grito en el suelo. Dibujos de Miguel Gallardo. Introducción de Jesús Maraña. Epílogo de Luis García Montero, Madrid, Visor.

- (2018): En román paladino. Prólogo de Emilio de Miguel Martínez. Epílogo de Luis García Montero, Úbeda, Fundación Huerta de san Antonio.

Sabina, JoAquín, y JaVier Menéndez FlóRes (2006): Sabina en carne viva. Yo también sé jugarme la boca, Barcelona, Ediciones B.

VAldeón, Julio (2017): Sabina. Sol y sombra, Valencia, Efe Eme.

Zamarro González, Justo (2017): Estética literaria en la obra de Joaquín Sabina: simbología de la desesperación en el cancionero. Tesis doctoral. Universidad de Viena. http://othes.univie. ac.at/49614/1/52104.pdf, acceso: 9-6-2021.

- (2019): Ciudad Sabina. Guía básica para sabineros, Madrid, Europa Ediciones. 